\title{
Scalp and Skull Reconstruction in Patients Irradiated for Tinea Capitis in Childhood: The Scalp Exchange Procedure
}

\author{
Ehud Fliss, MD ${ }^{1}$ Arik Zaretski, MD ${ }^{1} \quad$ Eyal D. Maoz-Halevy, MD ${ }^{2} \quad$ Eyal Gur, MD ${ }^{1}$ Ravit Yanko, MD ${ }^{1}$ \\ ${ }^{1}$ Department of Plastic and Reconstructive Surgery, The Microsurgery \\ Unit, Tel-Aviv Sourasky Medical Center, Affiliated with the Sackler \\ Faculty of Medicine, Tel-Aviv University, Tel-Aviv, Israel \\ 2 Department of Neurology, Sheba Medical Center affiliated with the \\ Sackler Faculty of Medicine, Tel-Aviv University, Tel-Aviv, Israel \\ Address for correspondence Ravit Yanko, MD, Department of Plastic \\ and Reconstructive Surgery, Tel-Aviv Sourasky Medical Center, \\ 6 Weizman Street, Tel-Aviv 6423906, Israel \\ (e-mail: ravity11@gmail.com). \\ J Reconstr Microsurg Open 2020;5:e61-e68.
}

\begin{abstract}
Background Approximately 70,000 Israelis underwent scalp irradiation for tinea capitis infection during their childhood, as did many other children worldwide. Long-term follow-up data showed that these children had an increased risk of aggressive and multiple nonmelanoma skin cancers, meningiomas, and other malignancies. Resection of these lesions creates a defect of soft tissue, bone, and dura, and requires scalp and skull reconstruction with local or free flaps in the irradiated field.

Methods Sixteen patients with a history of childhood scalp irradiation underwent scalp and skull reconstruction in our department (2000-2018). Data on demographics, oncological status, operative details, and postoperative outcome were retrospectively collected and analyzed.

Results The study group included 11 males and 5 females (average age at surgery, 70 years). The most common lesions were meningiomas $(n=9)$ and basal cell carcinomas $(n=8)$, and the most common indication for reconstruction was chronic exposure of deep structures (skull, dura, brain tissue, and titanium mesh; $n=9$ ). Thirteen patients underwent primary free flap reconstruction and three underwent primary local flap reconstruction. Flap failure requiring reoperation occurred in one patient of the free flap reconstruction group (7\%) and in all three patients of the local flap reconstruction group.

\section{Keywords}

- microsurgery

- scalp reconstruction

- scalp irradiation

Conclusion Long-term consequences of childhood depilatory treatments of the scalp by irradiation are now surfacing. Our experience showed that in such cases, surgeons should aim for a more aggressive approach with wide resection and primary free flap reconstruction, and that favorable long-term functional and aesthetic results can safely be achieved using this reconstruction approach.
\end{abstract}

Between the 1930s and 1950s, X-ray epilation was widely used worldwide as primary treatment for tinea capitis (TC) infection. ${ }^{1,2}$ In Israel, approximately 70,000 people were treated during their childhood. The reported long-term consequences of this treatment include increased risk for nonmelanoma skin cancers (NMSC; relative risk [RR], 3.6-4.9), meningiomas (RR,
9.5), and other malignancies. ${ }^{3-7}$ These sequelae are becoming increasingly apparent in the past two decades due to the latency period of these pathologies. ${ }^{1}$ Typically, the nature of the skin tumors and meningiomas in this patient population is more aggressive than in the general population, and there may be a greater tendency of recurrence or development of received

February 26, 2020 accepted after revision July 9,2020
DOI https://doi.org/

10.1055/s-0040-1716418. ISSN 2377-0813.
Copyright $\odot 2020$ by Thieme Medical Publishers, Inc., 333 Seventh Avenue, New York, NY 10001, USA. Tel: +1(212) 760-0888.
License terms

() (1) $\Theta \circledast$ 
multiple primary lesions. ${ }^{6,7}$ Due to the poor skin quality and impairment of wound healing that follows radiation, many sustain local complications such as wound dehiscence and infection. Moreover, patients undergoing craniectomy or craniotomy are left with extruding foreign material through chronic wounds and require additional procedures in many cases. $^{8}$

Several aspects of the sequelae of childhood scalp irradiation have been studied, such as the type and prevalence of nonmelanoma skin cancers (NMSC) and meningioma appearance the genetic typing. ${ }^{1-3,9,10}$ However, to the best of our knowledge, complex scalp and/or skull reconstruction in this population have not been reported before. The purpose of this article is to present our experience in the reconstruction of scalp and skull defects in patients with a history of childhood $\mathrm{X}$-ray epilation for TC.

\section{Methods}

All consecutive patients with a history of childhood radiation for TC infection, who required and underwent complex scalp and skull reconstructive surgery at our institution between 2000 and 2018, were retrospectively analyzed. Following approval of the ethical institutional review board, their medical charts were reviewed, and the following data were retrieved: patient demographics (age, sex, etiology, and comorbidities) and flap characteristics (defect and flap components and recipient vessels). Their postoperative course and complications were recorded throughout the length of the follow-up period (at least 6 months).

Minor complications were defined as those requiring only conservative or medical interventions during hospital stay. Major complications were defined as those that required management with reoperation within 30 days or that resulted in admission to the intensive care unit or demise.

\section{Results}

\section{Patient and Lesion Characteristics}

A total of 16 patients with a history of childhood radiation therapy required complex scalp and skull reconstruction during the study period. The majority of patients were males ( $n=11$ ), and the average age at surgery was 70 years (range, 59-90 years; - Table 1). The lesions included multiple and atypical meningioma (nine patients), recurrent basal cell carcinoma (BCC; eight patients), osteoradionecrosis (ORN) and radiodermatitis (four patients), squamous cell carcinoma (SCC, two patients), and myxofibrosarcoma (one patient). Five patients had a combination of tumors, consisting of meningioma and BCC. The size of the defect ranged from $5.7 \mathrm{~cm} \times 2.5 \mathrm{~cm}$ and up to $10.3 \mathrm{~cm} \times 13.5 \mathrm{~cm}$ with a mean surface area of $70.5 \mathrm{~cm}^{2}$. Nine patients underwent additional irradiation as adjunctive treatment for the current pathology. Eight patients had undergone a previous craniotomy and/or craniectomy with titanium mesh insertion, and three of them underwent repeated resections due to recurrence of meningioma. The most common indication for scalp and/or skull resection and reconstruction was a chronic osteocuta-
Table 1 Patients and preoperative characteristics

\begin{tabular}{|l|l|l|l|}
\hline & $n(\%)$ & Mean & Range \\
\hline Total & $16(100)$ & & \\
\hline Male gender & $11(68)$ & & \\
\hline Age at surgery (y) & & 70 & $59-90$ \\
\hline Lesion & & & \\
\hline Meningioma & $9(56)$ & & \\
\hline Basal cell carcinoma & $8(50)$ & & \\
\hline $\begin{array}{l}\text { Osteoradionecrosis } \\
\text { and radiodermatitis }\end{array}$ & $4(25)$ & & \\
\hline Squamous cell carcinoma & $2(12)$ & & \\
\hline Myxofibrosarcoma & $1(6)$ & & \\
\hline Multiple lesions & $5(31)$ & & \\
\hline Defect surface area (cm $\left.{ }^{2}\right)^{\mathrm{a}}$ & & 70.5 & $14.2-139$ \\
\hline Prior treatment & & & \\
\hline Radiation & $9(56)$ & & \\
\hline Craniotomy/craniectomy & $8(50)$ & & \\
\hline Cranioplasty & $2(12)$ & & \\
\hline Skull burring & $2(12)$ & & \\
\hline Local 5 FU & $1(6)$ & & \\
\hline $\begin{array}{l}\text { Indication for scalp } \\
\text { and/or skull reconstruction }\end{array}$ & $9(56)$ & & \\
\hline $\begin{array}{l}\text { Chronic sinus/foreign } \\
\text { material exposure }\end{array}$ & $3(18)$ & & \\
\hline $\begin{array}{l}\text { Intracranial tumor } \\
\text { involving skin }\end{array}$ & $2(12)$ & & \\
\hline Large skin tumor & $2(12)$ & & \\
\hline Unknown & & & \\
\hline
\end{tabular}

${ }^{\mathrm{a}}$ Missing for four patients.

neous sinus or exposure of deep structures (skull, dura, brain tissue, and titanium mesh) that was sustained by nine patients. Intracranial tumor involving the skin was the indication in additional three patients and a rare sarcoma (fibromyxosarcoma) in one patient.

\section{Surgery}

Sixteen free tissue transfers were performed in 14 patients. A free flap was performed as the primary mode of reconstruction in 13 patients, and an additional three were performed as salvage procedures for failed reconstruction ( - Table 2 ). The most common method of reconstruction was a free latissimus dorsi (LD) flap with or without a fascia lata graft and splitthickness skin graft (STSG; $n=10$ ). The superficial temporal vessels were the most common recipient vessels when a free flap was used $(n=13)$ with no need for vein grafts. Anastomosis to the superficial temporal vessels was performed at the level of the tragus, or slightly more proximal, without disrupting the parotid gland. Local flaps were used as primary mode of reconstruction in three patients. These three patients underwent a total of seven surgeries (six repeated local flaps and one free flap) due to partial or complete lap failure. 
Table 2 Clinical and operative course

\begin{tabular}{|c|c|c|c|c|c|c|c|c|c|}
\hline $\mathrm{Pt}$ & Age (y) & Lesion & Defect & $\begin{array}{l}\text { Defect } \\
\text { size }(\mathrm{cm})\end{array}$ & $\begin{array}{l}\text { Primary } \\
\text { local } \\
\text { flap }\end{array}$ & $\begin{array}{l}\text { Primary } \\
\text { free } \\
\text { flap }\end{array}$ & $\begin{array}{l}\text { Secondary } \\
\text { reconstruction }\end{array}$ & $\begin{array}{l}\text { Free } \\
\text { flap }\end{array}$ & $\begin{array}{l}\text { Recipient } \\
\text { vessels }\end{array}$ \\
\hline 001 & 65 & $\begin{array}{l}\text { Multiple } \\
\text { meningiomas } \\
\text { and BCC }\end{array}$ & Scalp, calvaria & $9.5 \times 6.5$ & - & + & - & LD & ST \\
\hline 002 & 59 & $\begin{array}{l}\text { Multiple } \\
\text { meningiomas } \\
\text { and BCC }\end{array}$ & Scalp, calvaria & Missing & - & + & - & $\mathrm{LD}$ & ST \\
\hline 003 & 68 & Multiple BCC & Scalp, calvaria & $12 \times 9$ & - & + & - & LD & ST \\
\hline 004 & 69 & ORN & $\begin{array}{l}\text { Scalp, calvaria, } \\
\text { dura, brain }\end{array}$ & $6.5 \times 5$ & + & - & Local flap X 2 & - & NA \\
\hline 005 & 67 & Multiple BCC & Scalp, calvaria & Missing & - & + & - & LD & ST \\
\hline 006 & 90 & Multiple BCC & $\begin{array}{l}\text { Scalp, calvaria, } \\
\text { dura, brain }\end{array}$ & $12 \times 9.5$ & - & + & - & LD & $\mathrm{F}$ \\
\hline 007 & 61 & $\begin{array}{l}\text { Multiple } \\
\text { meningiomas }\end{array}$ & $\begin{array}{l}\text { Scalp, calvaria, } \\
\text { dura }\end{array}$ & $6.5 \times 3$ & - & + & - & RA & ST \\
\hline 008 & 63 & SCC & Scalp, calvaria & $14 \times 9$ & - & + & - & LD & ST \\
\hline 009 & 77 & BCC and SCC & Scalp, calvaria & $10 \times 5$ & - & + & - & LD & ST \\
\hline 010 & 67 & $\begin{array}{l}\text { Multiple } \\
\text { meningiomas } \\
\text { and BCC }\end{array}$ & Scalp, calvaria & $8.5 \times 5.5$ & + & - & Local flap & - & NA \\
\hline 011 & 69 & $\begin{array}{l}\text { Atypical } \\
\text { meningioma }\end{array}$ & $\begin{array}{l}\text { Scalp, calvaria, } \\
\text { dura }\end{array}$ & Missing & - & + & Free flap & $\mathrm{LD} \rightarrow \mathrm{ALT}$ & $\mathrm{ST}+\mathrm{ST}$ \\
\hline 012 & 64 & $\begin{array}{l}\text { Multiple } \\
\text { meningiomas } \\
\text { and BCC }\end{array}$ & $\begin{array}{l}\text { Scalp, calvaria, } \\
\text { dura }\end{array}$ & $8 \times 4.6$ & - & + & - & TDAP & ST \\
\hline 013 & 71 & $\begin{array}{l}\text { Recurrent } \\
\text { meningioma }\end{array}$ & $\begin{array}{l}\text { Scalp, calvaria, } \\
\text { dura }\end{array}$ & $8.5 \times 5.5$ & - & + & - & ALT & $\mathrm{F}$ \\
\hline 014 & 70 & $\begin{array}{l}\text { Recurrent } \\
\text { meningioma }\end{array}$ & $\begin{array}{l}\text { Scalp, calvaria, } \\
\text { dura }\end{array}$ & $5.7 \times 2.5$ & - & + & - & ALT & $\mathrm{F}$ \\
\hline 015 & 73 & Fibromyxosarcoma & $\begin{array}{l}\text { Scalp, calvaria, } \\
\text { dura }\end{array}$ & $10.3 \times 13.5$ & - & + & - & LD & ST \\
\hline 016 & 78 & $\begin{array}{l}\text { Atypical } \\
\text { meningioma }\end{array}$ & Scalp, calvaria & Missing & + & - & $\begin{array}{l}\text { Local flap } \rightarrow \\
\text { Free flap } \times 2\end{array}$ & $\mathrm{ALT} \rightarrow \mathrm{LD}$ & $\mathrm{ST}+\mathrm{ST}$ \\
\hline
\end{tabular}

Abbreviations: ALT, anterolateral thigh; BCC, basal cell carcinoma; F, facial vessels; LD, latissimus dorsi; NA, not applicable; ORN, osteoradionecrosis; RA, rectus abdominis; SCC, squamous cell carcinoma; ST, superficial temporal vessels; TDAP, thoracodorsal artery perforator.

\section{Complications}

Three patients of the free flap group sustained major complications, including one case of mortality (30-day postoperatively) and two cases of complete flap failure that required reoperation with repeated free flap reconstruction (- Table 3 ). In both of these cases, flap failure appeared due to arterial thrombosis and flap necrosis, though one of the cases appeared at postoperative day 15 , with diffuse patches of necrosis progressing to complete necrosis. There was a $100 \%$ rate of major complications among the three patients in the local flap group, with all cases resulting in partial flap loss and reconstructive failure requiring reoperation. Two of these patients underwent repeated local flap reconstruction and one underwent secondary free flap reconstruction. Neurological complications appeared in six patients, all of whom were in the free flap group. Donor site morbidity in the free flap group included dehiscence and seroma in two patients each and surgical site infection in one patient, all of which resolved with conservative measures. Recurrence of malignancy was observed in two patients, both involving recurrence of meningiomas: both patients were in the free flap group and both subsequently received additional irradiation treatment.

\section{Discussion}

The aim of this study was to describe the characteristics, pathology, and course of patients requiring complex scalp reconstruction in a population radiated for TC in childhood. During the 1930 s to 1950 s, roentgen ray epilation by means of the Keinbock-Adamson technique was considered a safe and efficient method for treating TC in children. ${ }^{6,11-13}$ Long-term follow-up of these children showed an increased risk for NMSC of the head and neck (RR, 3.6-4.9) and meningiomas (RR, 9.5), as well as for other rarer malignancies. ${ }^{1,3-7,12,14,15}$ Increased risk of death from any cancer was observed by some, with an RR of $1.7 .^{15}$ Several studies reported a latency period of 12 to 
Table 3 Postoperative Complications

\begin{tabular}{|c|c|c|}
\hline & $\begin{array}{l}\text { Free flap } \\
\text { reconstruction } \\
n(\%)\end{array}$ & $\begin{array}{l}\text { Local flap } \\
\text { reconstruction } \\
n(\%)\end{array}$ \\
\hline Total no. of patients & 13 & 3 \\
\hline Total no. of flaps & 16 & 6 \\
\hline $\begin{array}{l}\text { Major complications } \\
\text { (of total flaps) }^{\mathrm{a}}\end{array}$ & $3(19)$ & $6(100)$ \\
\hline 30-day mortality & $1(8)$ & $0(0)$ \\
\hline \multicolumn{3}{|c|}{ Acute neurological complications (of all 16 patients) } \\
\hline $\begin{array}{l}\text { Brain abscess/infected } \\
\text { CSF collection }\end{array}$ & $3(23)$ & $0(0)$ \\
\hline CSF leak & $2(15)$ & $0(0)$ \\
\hline Bacterial meningitis & $1(8)$ & $0(0)$ \\
\hline Subdural hematoma & $1(8)$ & $0(0)$ \\
\hline $\begin{array}{l}\text { Seizures due to } \\
\text { brain edema }\end{array}$ & $1(8)$ & $0(0)$ \\
\hline \multicolumn{3}{|c|}{ Recipient site complications (of total flaps) } \\
\hline Total flap loss & $2(12)$ & $1(17)$ \\
\hline Partial flap loss & $1(6)$ & $4(60)$ \\
\hline Surgical site infection & $3(19)$ & $0(0)$ \\
\hline Dehiscence & $2(12)$ & $3(50)$ \\
\hline \multicolumn{3}{|c|}{ Donor site complications (of total flaps) ${ }^{b}$} \\
\hline Dehiscence & $2(12)$ & $0(0)$ \\
\hline Seroma & $2(12)$ & $0(0)$ \\
\hline Surgical site infection & $1(6)$ & $0(0)$ \\
\hline \multicolumn{3}{|l|}{ Recurrence } \\
\hline Meningioma & $2(11)$ & $0(0)$ \\
\hline Additional irradiation & $2(11)$ & $0(0)$ \\
\hline
\end{tabular}

Abbreviation: CSF, cerebrospinal fluid.

${ }^{a}$ Mortality, complete flap failure, complete or partial flap failure requiring re-operation, hemorrhage requiring re-operation, any complication causing permanent neurological sequelae.

${ }^{\mathrm{b}}$ All donor site complications resolved with conservative measures.

50 years for the first tumor diagnosis. ${ }^{6,8,9}$ In our study population, it was impossible to precisely determine the latency period until the index procedure, since the exact year of radiation was unknown and patients arrived after they had undergone various procedures for the same pathology. However, having performed complex scalp reconstruction approximately 15 years following initial diagnosis in most cases, we can roughly assume that 40 to 58 years had elapsed since the exposure to radiation in childhood.

Meningioma was the most common tumor and BCC was the most common skin cancer in our study cohort. Radiationinduced meningiomas tend to appear at a younger age than in nonirradiated patients ( $42-45$ vs. 60 years), with a higher rate of recurrence (18 vs. $14 \%$ ), of calvarial involvement (59 vs. $38 \%$ ), and proportion of multiple lesions (15.8 vs. $2.4 \%$ ) in comparison to nonradiation-induced meningiomas. ${ }^{9}$ The latency period is reported as being in a range of 4 to 50 years after irradiation, with a median age of 34 years. ${ }^{6,8,9}$ BCCs arising in childhood-irradiated patients do not genetically differ from sporadic BCCs; however, numerous cohort studies have shown that the former tends to be recurrent, multifocal, more aggressive, and likely to carry the tendency to metastasize. ${ }^{1,4-6,10,12,13}$

An estimated 20,000 children were treated for TC with irradiation in Israel, and an additional 50,000 were treated prior to immigrating to Israel. ${ }^{1,2,9,15}$ Many earlier studies focused on the prevalence of the resulting pathologies and compared their prevalence and characteristics to those pathologies in the general population. ${ }^{2-5,7-10,14}$ We believe, this is the first study to describe the characteristics of a cohort of patients that received childhood depilatory-treatment, the specific pathologies that were encountered, and the details of the surgical interventions for treating complex scalp defects.

\section{Population-Specific Considerations}

The current results demonstrated that patients may present with more than one diagnosis, and that the diagnosis may be rare, such as ORN and sarcomas. This finding is significant in the planning and execution of the ablative surgery, and points to the need for consulting appropriate expert medical and surgical colleagues such as neurosurgeons, dermatologists, and neurooncologists. Another unique trait of this group is that a free flap may be a necessity, even in a setting where skin coverage per se is not the goal. Eight of our patients presented with an intracranial tumor, but it was decided that a durable primary closure would not be feasible at the end of the surgery without later having to deal with dehiscence or skin necrosis, as the scalp was so atrophic and adherent. The radiation field is wide and its damage is uniform to all tissues that cross its path, as opposed to modern radiation, where the fields are planned to minimize the collateral mutilation. Even when minor scalp flaps were used to aid tension-free closure, those flaps displayed impaired viability and healing and required a reoperation and the later use of a free flap in three cases (-Figs. 1 and 2). The risk must be estimated in advance, and disciplines, such as neurosurgery, dermatology, and neurooncology, should be educated, of the possibility of a larger scale surgery and collaboration with reconstructive plastic surgeons.

Lastly, due to the prolonged latency period, since undergoing radiation, most of these patients are of advanced age when they require complex scalp reconstruction. The average age of our cohort was 70 years. Others had observed that old age per se is not a factor in free flap survival, but some have suggested that it may contribute to medical complications that may arise after such a complex surgery. ${ }^{16-19}$ There were surprisingly few significant comorbidities among our patients (no active coronary artery disease, two heavy smokers, and one diabetic), which may have resulted in such low medical complication rates. Van Driel et al ${ }^{16}$ summarized the complications reported in a series of free flap scalp reconstructions and found a perioperative death rate of 0 to $3.6 \%$. Afifi et al ${ }^{20}$ reported a single death in a series of 13 patients with scalp and bone reconstruction.

\section{Surgical Considerations}

The use of the "reconstructive elevator" may be more appropriate than the "reconstructive ladder" paradigm for irradiated scalp defects. ${ }^{21,22}$ Free flap reconstruction enables a more 

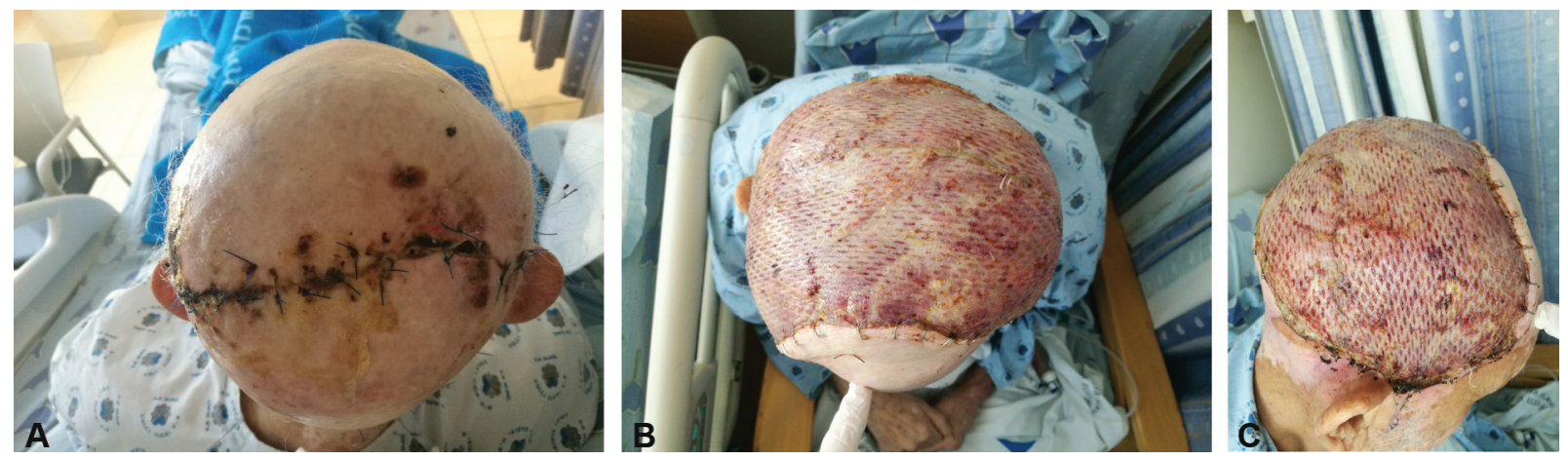

Fig. 1 A 78-year-old male with recurrent atypical meningiomas following childhood irradiation to the scalp for TC. He had earlier undergone resection of a meningioma, craniotomy, and cranioplasty and received additional irradiation. (A) Following resection of a recurrent meningioma and reconstruction with a titanium mesh and local scalp flaps. Note partial flap necrosis, dehiscence and mesh exposure. (B, C) Following wide resection of injured scalp and reconstruction with free LD and STSG. LD, latissimus dorsi; STSG, split-thickness skin graft.
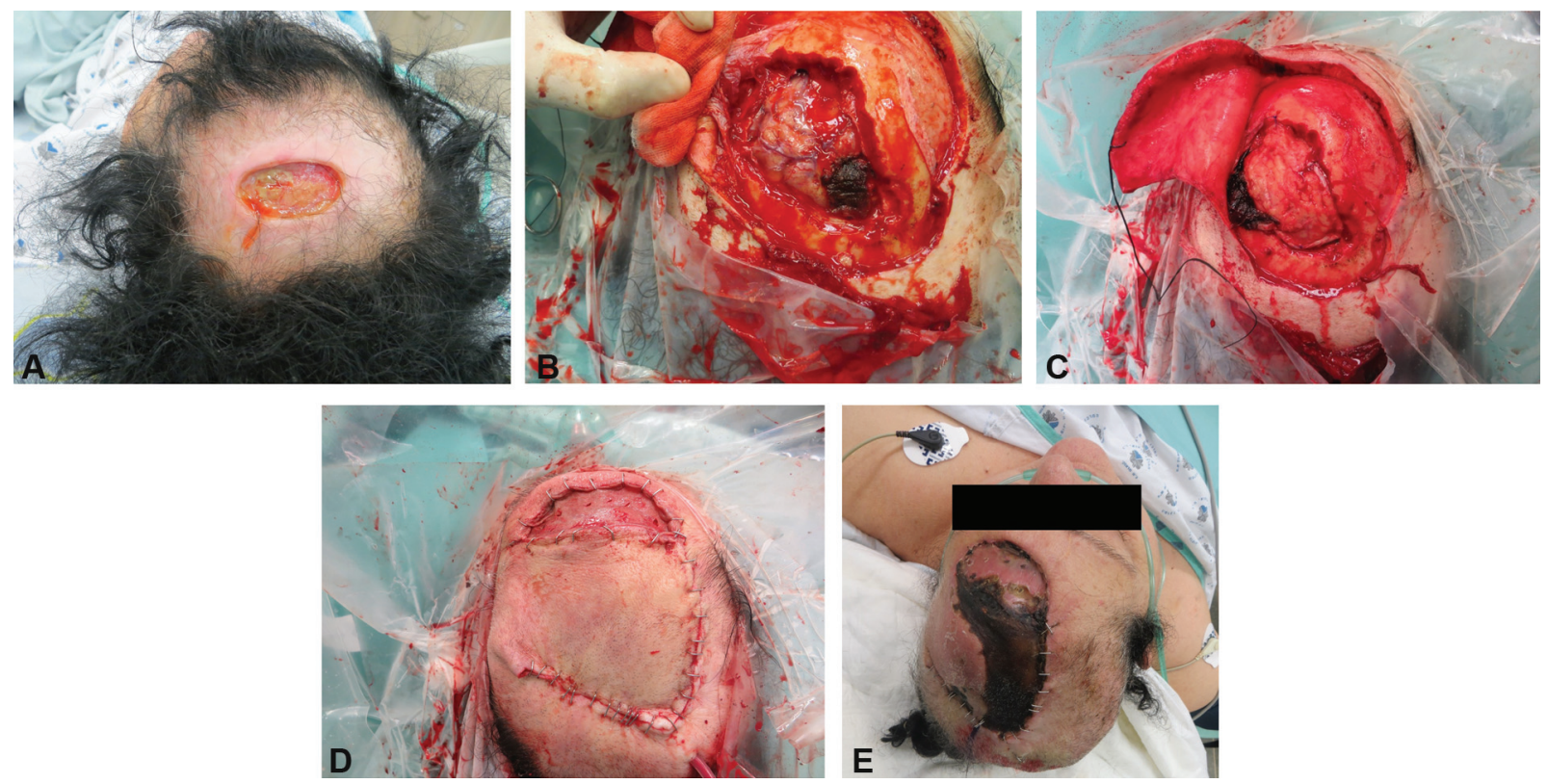

Fig. 2 A 69-year-old female with chronic osteoradionecrosis following childhood scalp irradiation for TC who was admitted with exposed brain parenchyma. (A) Preoperative photo. (B) Intraoperative photo following wide resection and debridement. (C, D) Intraoperative photo following closure with a fascia lata graft for brain coverage and a local scalp flap. (E) Postoperative day 15: necrosis of most of the flap. TC, tinea capitis.

radical resection, thus increasing the likelihood of removing the tumor and/or damaged tissues with malignant potential and replacing it with a well-vascularized bulk of healthy soft tissue. $^{22,23}$ We call this procedure "scalp exchange," since the aim is to remove all the tissues that had become malignant and that may be at risk of malignant transformation, and to replace them with nonaffected tissues in the form of a free flap (-Fig. 3). There is close collaboration between our microsurgical and neurosurgical teams in patient evaluation, and frequent assistance in surgical planning of all patients whose scalps were radiated for TC in childhood.

The accepted approach for scalp defects is that those less than 6 to $8 \mathrm{~cm}$ within hair-bearing scalp can be treated by local flaps with or without skin grafts. ${ }^{1,17,18,21,24,25}$ However, a free flap should be considered in cases of previous radiation, exposed dura, multiple previous surgeries, and contaminated cranioplasty regardless of defect size. ${ }^{17,19,24-26}$ In the current series, all the patients were irradiated and, indeed, they all required a free flap at some point in their clinical course. Three patients initially underwent local flap reconstruction, all of which failed. One patient was not a candidate for free flap reconstruction due to her medical and psychiatric background, despite having a clear indication for a larger scale surgery. The other two did not have an initial skin defect, and closure with minimal local rotation flaps was performed to facilitate primary closure of an operation performed for intracranial indications. Even those minimal flaps led to skin necrosis and breakdown of the wound, requiring repeated surgery and long-term local treatment.

We used the LD muscle flap in 10 of all the 16 free flaps performed. Advantages of this approach include the flap size that enables coverage of large defects, its reliable anatomy, and the low donor site morbidity. ${ }^{16,18,19,22,23}$ To shorten surgery time, we performed simultaneous harvest and resection by 

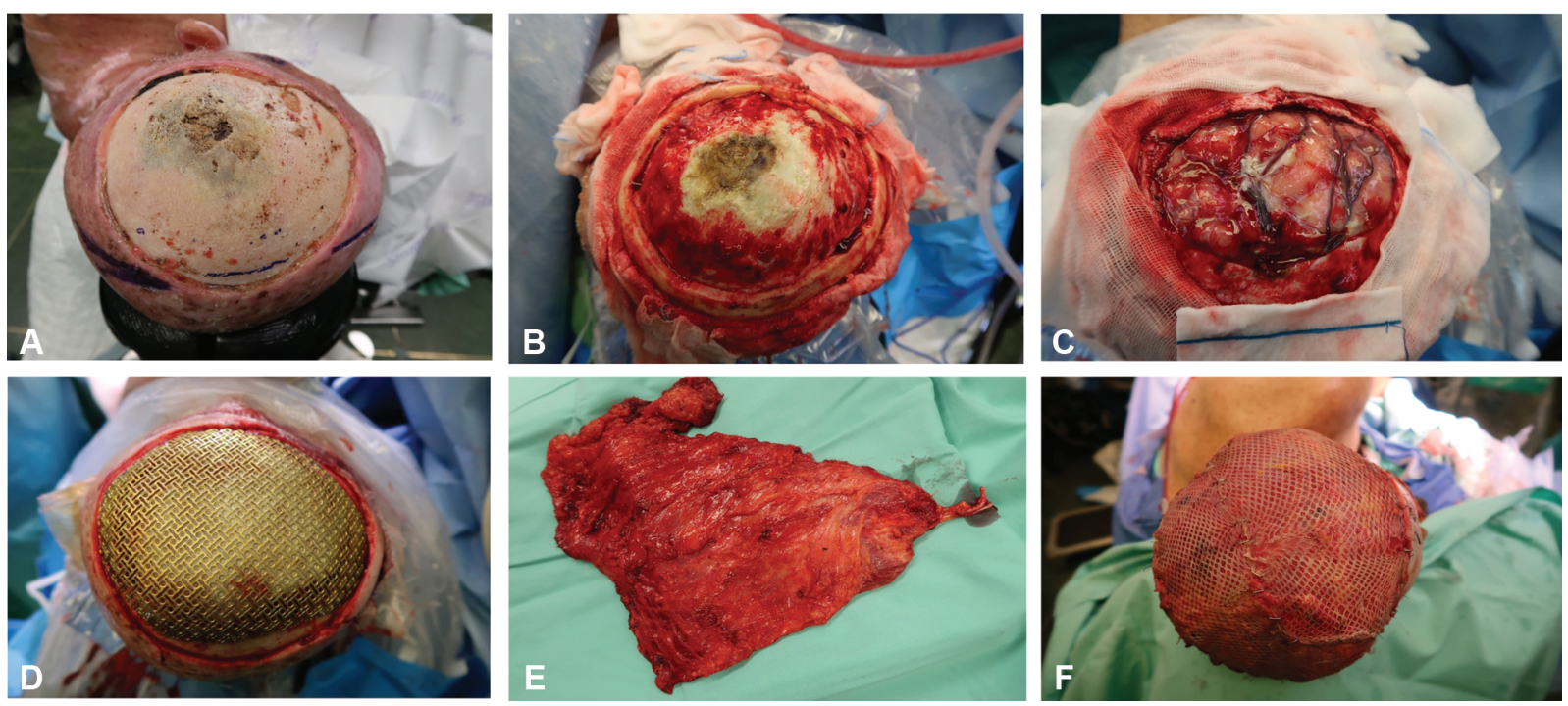

Fig. 3 A 73-year-old male with history of childhood scalp irradiation for TC, presented with long-standing ulcerated myxofibrosarcoma of the scalp with exposed dura. (A) Preoperative photo. (B) Intraoperative photo following wide excision of scalp and burring of viable bone. (C) Following debridement of necrotic bone and dura with exposure of brain parenchyma. (D) Following reconstruction with fascia lata graft for brain coverage and titanium mesh. (E, F) Completed reconstruction with free LD and STSG. LD, latissimus dorsi; STSG, split-thickness skin graft; TC, tinea capitis.

positioning the patient in a "sloppy" lateral decubitus with the hand mobile and scrubbed into the surgical field and with the head placed on a headrest to allow more space around the head and body for two teams.

An anterolateral thigh (ALT) fasciocutaneous flap is another option, and it has several advantages over the LD muscle flap. It allows for supine positioning and a roomy two-team approach that may shorten surgery time, together with a long pedicle that comfortably allows anastomosis to the facial vessels without the need of vein grafts. ${ }^{19,20}$ Being as it is a fasciocutaneous flap, it does not atrophy and maintains its thickness, which may be an advantage if hardware is used under the flap or if additional radiation is needed. ${ }^{16,19,20,22}$ The ALT is most appropriate for small-to-medium-sized defects, but not for a whole scalp exchange, as its size is limited to allow primary closure of the donor site. We used this flap as first choice for three patients in this study of all 13 primary free flaps, and later in an additional patient as a salvage procedure. Studies comparing the ALT and LD flaps have shown equivalent results in terms of immediate minor complications and long-term results. ${ }^{19}$

We used a fascia lata graft in six patients when the indication was an intracranial tumor or when there was intracranial involvement of ORN, as well as for cases in which the native dura had been violated, and the use of synthetic dura substitutes was contraindicated. In two additional patients, the ALT flap was taken with a larger fascial component that was sutured to the native dura edges or tucked under the edges of the cranium as a barrier to cerebrospinal fluid (CSF) leakage. $^{20,24}$ This reconstruction precludes the use of titanium, since the fascia is inherently attached to the undersurface of the flap's skin.

\section{Population-Specific Complications}

We assessed reconstruction-related, as well as neurosurgical complications. Analysis of flap survival in the free flap group revealed two cases of flap loss in 16 flap patients, two cases of minor dehiscence, and one case of partial flap loss that required prolonged wound treatment but not additional surgery. The rate of free flap failure in scalp reconstruction is reported as being 0 to $6 \%$ in most series, with an additional $6 \%$ of partial flap failure occasionally requiring an additional free or local flap for complete healing. ${ }^{16-19,27}$ We consider the higher percentage of total flap failure in our group (12.5\%) compared with the 6\% cited in the literature is probably attributable to our small cohort. All of the local flaps had partial or complete flap failure. One patient underwent secondary free flap reconstruction, and two others remained with draining sinuses under conservative treatment and were not scheduled for a free flap due to their poor general medical condition. The findings in our study support those which consider previous radiation treatment and multiple surgeries a relative contraindication for locally based reconstruction. ${ }^{27}$

Six of our patients sustained early neurosurgical complications, all appearing in the free flap group. Three of them had more than one complication. Four patients had intracranial infections (infected CSF collection, brain abscess, and bacterial meningitis). Infections are reported to be quite prevalent in these settings, and are more commonly associated with immediate cranioplasty, especially in the presence of a potentially contaminated wound, such as ORN, or chronic cancerous ulcers. $^{19,20}$ One of our patients had a hematoma requiring reoperation, and three patients had either increased intracranial pressure or a CSF leak requiring the placement of a continuous drainage catheter. One patient developed brain edema, seizures, and hemiparesis requiring steroid treatment and anticonvulsants.

Our "go-to" flap is the free LD muscle flap anastomosed to the superficial temporal vessels, with or without a fascia lata graft for dura replacement and with a split-thickness skin graft cover. There are several advantages to this approach. 

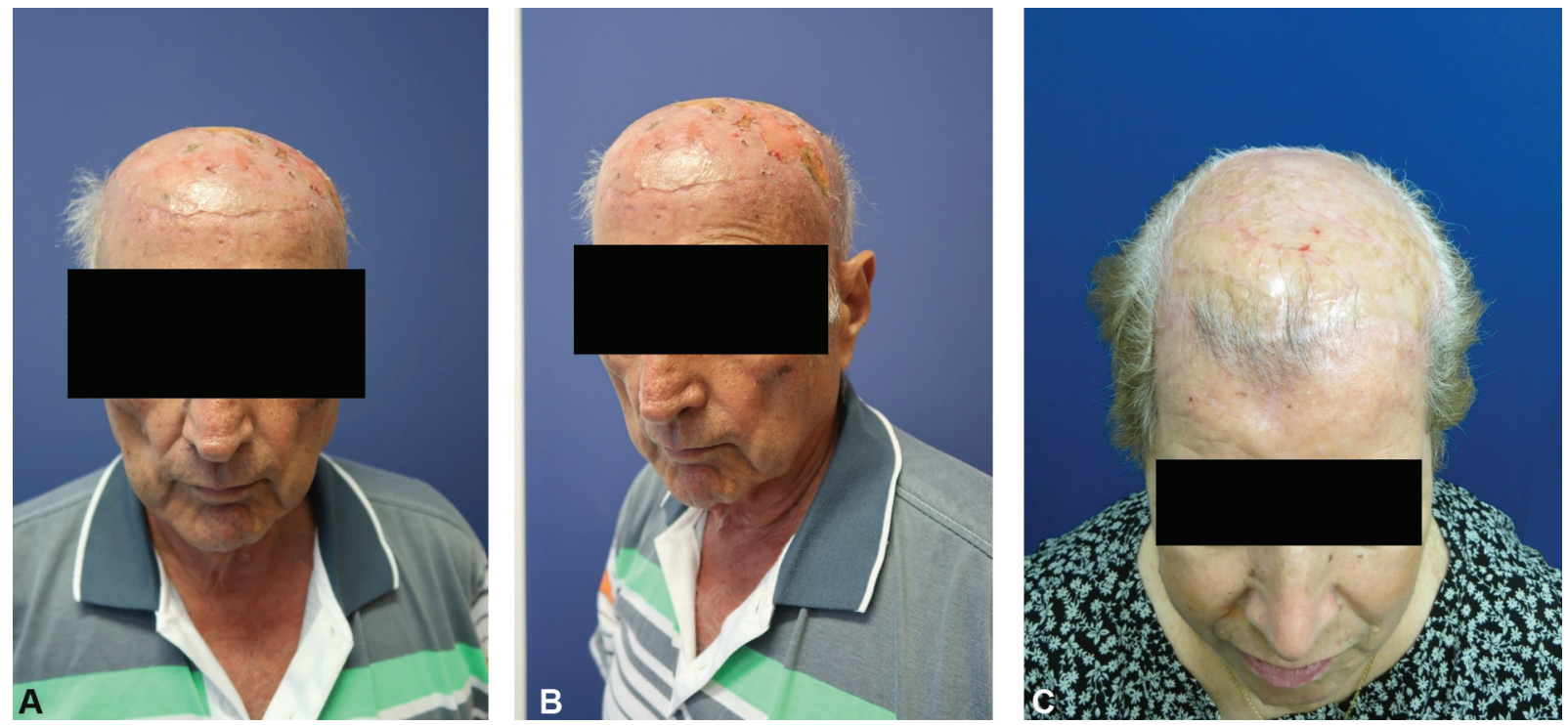

Fig. 4 Postoperative photos following scalp exchange with a free latissimus dorsi flap and split-thickness skin graft. (A, B) At 3 months postoperatively. (C) At 1 year postoperatively.

First, by removing more of the injured and irradiated skin, greater likelihood of successful wound healing can be expected, with lower risk of wound complications. Second, wide resection improves field cancerization control and reduces the risk of positive margins and later recurrence. ${ }^{18,22}$ Third, coverage of these complex chronic wounds with a myocutaneous free flap aids in eradicating smoldering chronic infection, including osteomyelitis and contaminated foreign material. Fourth, adding a fascial layer (either as a fasciocutaneous flap or by adding a fascia lata graft) allows reconstruction of dural defects, as well as a more definite resection of the primary pathology. Favorable long-term functional and aesthetic results can be achieved using this method in this specific subgroup of patients (-Fig. 4).

\section{Conclusion}

Our experience in treating and following a cohort of adult patients with scalp and skull reconstruction irradiated for TC in childhood leads us to conclude that repeated small scale and local procedures do not provide satisfactory long-term results in the majority of cases. Surrounding tissues are heavily damaged, and their use for local tissue transfer is unreliable. As opposed to the population of patients that have received focal radiation for a singular lesion, here the radiation is scattered, thus affecting the whole perimeter, resulting in field cancerization. Therefore, we favor taking a more aggressive approach and, given no absolute contraindications, we recommend a scalp exchange with radical resection of the malignant lesion, removal of the surrounding injured tissue, and immediate free flap reconstruction.

Note

This study was presented at The 45th Israeli Society of Plastic and Aesthetic Surgery (ISPAS) annual meeting 2018. The authors declare conforming to the Declaration of Helsinki (local Institutional Review Board no.: 0599-19-TLV).

\section{Authors' Contributions}

All authors have contributed to the study design, drafting, and reviewing of the manuscript and have approved it submission.

\section{Funding}

None.

\section{Conflict of Interest}

None declared.

\section{References}

1 Tessone A, Amariglio N, Weissman O, et al. Radiotherapy-induced basal cell carcinomas of the scalp: are they genetically different? Aesthetic Plast Surg 2012;36(06):1387-1392

2 Ronel DN, Schwager RG, Avram MR. Squamous cell carcinoma of the scalp after radiotherapy for tinea capitis. Dermatol Surg 2004; 30(03):446-449

3 Ekmekçi P, Bostanci S, Anadolu R, Erdem C, Gürgey E. Multiple basal cell carcinomas developed after radiation therapy for tinea capitis: a case report. Dermatol Surg 2001;27(07): 667-669

4 Karagas MR, McDonald JA, Greenberg ER, et al; For The Skin Cancer Prevention Study Group. Risk of basal cell and squamous cell skin cancers after ionizing radiation therapy. J Natl Cancer Inst 1996;88(24):1848-1853

5 Boaventura P, Oliveira R, Pereira D, Soares P, Teixeira-Gomes J. Head and neck basal cell carcinoma prevalence in individuals submitted to childhood X-ray epilation for tinea capitis treatment. Eur J Dermatol 2012;22(02):225-230

6 Maalej M, Frikha H, Kochbati L, et al. Radio-induced malignancies of the scalp about 98 patients with 150 lesions and literature review. Cancer Radiother 2004;8(02):81-87

7 Caccialanza M, Piccinno R, Brambati M. Relapsing meningiomas and multiple basal cell carcinomas after x-ray epilation for tinea capitis. Int J Dermatol 2012;51(07):880-881

8 Umansky F, Shoshan Y, Rosenthal G, Fraifeld S, Spektor S. Radiation-induced meningioma. Neurosurg Focus 2008;24(05):E7

9 Sadetzki S, Flint-Richter P, Ben-Tal T, Nass D. Radiation-induced meningioma: a descriptive study of 253 cases. J Neurosurg 2002; 97(05):1078-1082 
10 Hassanpour SE, Kalantar-Hormozi A, Motamed S, Moosavizadeh SM, Shahverdiani R. Basal cell carcinoma of scalp in patients with history of childhood therapeutic radiation: a retrospective study and comparison to nonirradiated patients. Ann Plast Surg 2006; 57(05):509-512

11 Crossland PM. Therapy of tinea capitis; the value of x-ray epilation. Calif Med 1956;84(05):351-353

12 Pousti A. Malignant tumours of the scalp resulting from X-ray treatment of tinea capitis. Br J Plast Surg 1979;32(01):52-54

13 Tauber G, Pavlovsky L, Fenig E, Hodak E. Vismodegib for radiationinduced multiple basal cell carcinomas (BCCs) of the scalp. J Am Acad Dermatol 2015;73(05):799-801

14 Sawyer AR, McGoldrick RB, Mackey SP, Powell B, Pohl M. Malignant melanoma following scalp irradiation for tinea capitis. J Plast Reconstr Aesthet Surg 2007;60(11):1239-1240

15 Ron E, Modan B, Boice JD Jr. Mortality after radiotherapy for ringworm of the scalp. Am J Epidemiol 1988;127(04):713-725

16 van Driel AA, Mureau MA, Goldstein DP, et al. Aesthetic and oncologic outcome after microsurgical reconstruction of complex scalp and forehead defects after malignant tumor resection: an algorithm for treatment. Plast Reconstr Surg 2010;126(02):460-470

17 Simunovic F, Eisenhardt SU, Penna V, Thiele JR, Stark GB, Bannasch $\mathrm{H}$. Microsurgical reconstruction of oncological scalp defects in the elderly. J Plast Reconstr Aesthet Surg 2016;69(07):912-919

18 McCombe D, Donato R, Hofer SO, Morrison W. Free flaps in the treatment of locally advanced malignancy of the scalp and forehead. Ann Plast Surg 2002;48(06):600-606

19 Fischer JP, Sieber B, Nelson JA, et al. A 15-year experience of complex scalp reconstruction using free tissue transfer-analysis of risk factors for complications. J Reconstr Microsurg 2013;29 (02):89-97

20 Afifi A, Djohan RS, Hammert W, Papay FA, Barnett AE, Zins JE. Lessons learned reconstructing complex scalp defects using free flaps and a cranioplasty in one stage. J Craniofac Surg 2010;21 (04):1205-1209

21 Lutz BS, Wei FC, Chen HC, Lin CH, Wei CY. Reconstruction of scalp defects with free flaps in 30 cases. Br J Plast Surg 1998;51(03): 186-190

22 Labow BI, Rosen H, Pap SA, Upton J. Microsurgical reconstruction: a more conservative method of managing large scalp defects? J Reconstr Microsurg 2009;25(08):465-474

23 Hierner R, van Loon J, Goffin J, van Calenbergh F. Free latissimus dorsi flap transfer for subtotal scalp and cranium defect reconstruction: report of 7 cases. Microsurgery 2007;27(05):425-428

24 Chang KP, Lai CH, Chang CH, Lin CL, Lai CS, Lin SD. Free flap options for reconstruction of complicated scalp and calvarial defects: report of a series of cases and literature review. Microsurgery 2010;30(01):13-18

25 Desai SC, Sand JP, Sharon JD, Branham G, Nussenbaum B. Scalp reconstruction: an algorithmic approach and systematic review. JAMA Facial Plast Surg 2015;17(01):56-66

26 Stark J, Podda S, Szymanski K. Invasive squamous cell carcinoma of the scalp and calvarium: a multidisciplinary approach. Eplasty 2016;16:e29

27 Steiner D, Horch RE, Eyüpoglu I, et al. Reconstruction of composite defects of the scalp and neurocranium-a treatment algorithm from local flaps to combined AV loop free flap reconstruction. World J Surg Oncol 2018;16(01):217 